\title{
Alteraçóes Sensório-Motoras e Funcionalidade em Pacientes Acometidos com Acidente Vascular Cerebral
}

\section{Gustavo Christofoletti}

\begin{abstract}
Docente do curso de Fisioterapia da Universidade Federal de Mato Grosso do Sul, vice-coordenador da Residência Mutiprofissional em Saúde: Atenção ao Paciente Crítico e orientador do Programa de Pós-graduação em Saúde e Desenvolvimento do Centro-Oeste, Campo Grande-MS, Brasil.
\end{abstract}

A evolução do conhecimento científico e tecnológico, gerado a partir da caracterização e aprimoramento de novos métodos de prevenção, diagnóstico e reabilitação das afecçóes que comprometem a saúde humana, vem promovendo uma melhora na qualidade de vida dos indivíduos, repercutindo, assim, no aumento da expectativa de vida da população. Como consequência, relata o Instituto Brasileiro de Geografia e Estatística ${ }^{1}$, as estimativas para 2025 indicam que, no Brasil, a população idosa pode exceder 30 milhóes de pessoas, chegando a representar quase $13 \%$ da população do país. Em termos absolutos o Brasil passará de décimo sexto (1960) para o sexto lugar (2025) em indivíduos com mais de 60 anos $^{2}$.

Tendências observadas nas últimas décadas apontam para um o novo padrão demográfico no país, influenciado sobretudo pela redução da taxa de crescimento populacional e por transformaçóes profundas na composição de sua estrutura etária, com um significativo aumento no contingente de idosos. Estas modificações, por seu turno, têm imprimido importantes mudanças no perfil epidemiológico, com alteraçóes relevantes nos indicadores de saúde. Diante desta realidade, o acidente vascular cerebral vem ganhando destaque na comunidade científica, por ser uma afecção altamente prevalente em idades avançadas e caracterizar a condição clínica que apresenta maior risco de incapacidade na sociedade moderna ${ }^{3}$.

$\mathrm{O}$ artigo intitulado "Avaliação funcional de pacientes com acidente vascular cerebral utilizando o protocolo de Fugl-Meyer" é de grande relevância e se propóem a analisar a função sensório-motora dos pacientes, bem como observar possível correlação entre a idade, o tempo de tratamento e o comprometimento motor.
Conforme observado pelos autores, muitos pacientes apresentaram sinais clínicos características de lesóes neurológicas de áreas de projeção (áreas motoras e sensoriais primárias), causadas por possível comprometimento da artéria cerebral média - como evidenciado pelos sinais de plegia e anestesia com predomínio braquial na maioria dos casos analisados. Tal dado é importante por refletir boa parte dos episódios presentes na comunidade e possibilitar, diante disso, a generalizaçâo dos achados. Contudo, cabe dizer que além deste tipo de lesão há casos caracterizados por lesóes encefálicas em áreas associativas e, embora menos comuns que a primeira, são consideradas extremamente graves por gerar sinais de apraxia e agnosia.

Sobre o tratamento no acidente vascular cerebral, Langhammer e Lindmark ${ }^{5}$ demonstraram a importância da abordagem motora em pacientes que sofreram acidente vascular cerebral. Contudo, é apenas através de um diagnóstico cinético-funcional preciso que o profissional da saúde consegue elaborar um tratamento adequado. Nesse sentido, ao discutir tópicos e variáveis relacionadas à avaliação sensório-motora do paciente sequelado, Teles e Gusmão ${ }^{4}$ discorrem sobre a influência de tais fatores sobre as atividades funcionais do sujeito e estimulam a prescrição de uma abordagem motora adequada.

Por fim é importante lembrar que as escalas de avaliação funcional são usadas na prática da reabilitação e em pesquisa para diagnósticos, prognósticos e resposta a tratamentos. Mensuraçóes da recuperaçáo do paciente com sequelas provenientes de um acidente vascular cerebral normalmente focalizam a independência dos sujeitos nas atividades básicas e instrumentais de vida diária, confrontando com o comprometimento na função 
sensório-motora do paciente. A utilização do protocolo de Fugl-Meyer mostrou-se muito adequado, devido ao alto índice de confiabilidade intra e inter-observador que a escala possui, possibilitando a adequada replicabilidade dos achados obtidos ${ }^{6}$.

\section{REFERÊNCIAS}

1.Perfil dos idosos responsáveis pelos domicílios no Brasil (Endereço na Internet). Rio de Janeiro: Instituto Brasileiro de Geografia e Estatística (IBGE). (atualizado em: não informado; acessado em 03/2012). Disponivel em: <www. ibge.gov.br>.
2.Chaimowicz F. Health of the Brazilian elderly population on the eve of the 21st century: current problems, forecasts and alternatives. Rev Saúde Pub 1997;31:184-200.

3.Porcello MLC, Diogo LP, de Oliveira FM, Trentin S, Scalco RS, de Almeida AG, et al. Risk factors among stroke subtypes in Brazil. J Stroke Cerebrovasc Dis 2011, in press.

http://dx.doi.org/10.1016/j.jstrokecerebrovasdis.2011.05.022

4.Teles MS, Gusmão C. Avaliação funcional de pacientes com acidente vascular cerebral utilizando o protocolo de Fulg-Meyer. Rev Neurocienc 2012;20:42-9. 5.Langhammer B, Lindmark B. Functional exercise and physical fitness post streoke: the importance of exercise maintenance for motor control and physical fitness after stroke. Stroke Res Treat 2012; in press. doi:10.1155/2012/864835. http://dx.doi.org/10.1155/2012/864835

6.Maki T, Quagliato EMAB, Cacho EWA, Paz LPS, Nascimento NH, Inoue MMEA, Viana MA. Estudo de confiabilidade da aplicação da Escala de FuglMeyer no Brasil. Rev Bras Fisioter 2006;10:177-83.

http://dx.doi.org/10.1590/S1413-35552006000200007 